\title{
What Happens with Cow Behavior When Replacing Concrete Slatted Floor by Rubber Coating: A Case Study
}

\author{
S. Platz, ${ }^{\star 1}$ F. Ahrens, ${ }^{\star}$ J. Bendel, ${ }^{\star}$ H. H. D. Meyer, $†$ and M. H. Erhard* \\ *Department of Veterinary Science, Chair of Animal Welfare, Ethology, Animal Hygiene, and Animal Housing, Faculty of Veterinary Medicine, \\ Ludwig-Maximilians University, Munich, Germany \\ †Life and Food Science Centre, Chair of Physiology, Technical University, Munich/Freising-Weihenstephan, Germany
}

\begin{abstract}
An enhanced productive life cycle and improved animal welfare are aims pursued in dairy husbandry. This study assesses experimental observations on floor-associated behavior during the stepwise replacement of concrete slatted flooring by rubber mats. For this purpose, estrus (mounting) and hygiene behavior (licking while standing on 3 legs and caudal licking) within a herd of 50 loose-housed Brown Swiss dairy cows were analyzed by video observation before and after floor reconstruction. Still photographs and pedometers were used to asses step length and number of steps, representing walking behavior. Compared with the concrete floor surface, rubber coating led to an increase in step length (58 \pm 1 vs. $70 \pm 1 \mathrm{~cm} ; \mathrm{n}=35)$ and in steps per day $(4,226$ \pm 450 vs. $5,611 \pm 495$; mean $\pm \mathrm{SEM}$; $\mathrm{n}=9$ ). Mounting was higher on the flooring covered with rubber mats (23 vs. 112). Collapsing or slipping during mounting only occurred on concrete slatted flooring (in 19 out of 23 mounting actions). Licking while standing on 3 legs and caudal licking increased up to 4 -fold (105 vs. 511 observations). In conclusion, improvements were found in behavior when rubber-coated slatted floor surfaces were used in dairy cattle housing in transition from concrete flooring. Disorders in estrus and hygiene behavior were associated with the flooring of the barn and were relatively easy to investigate within the framework of farm welfare assessments.
\end{abstract}

Key words: dairy cattle, behavior, concrete floor, rubber covering

\section{INTRODUCTION}

Cow comfort can increase overall health, milk yield, and productive life because of enhanced animal welfare (Wagner-Storch et al., 2003). The commonly used con-

\footnotetext{
Received August 7, 2007.

Accepted November 16, 2007.

${ }^{1}$ Corresponding author: Siegfried.platz@tierhyg.vetmed. uni-muenchen.de
}

crete slatted floor in loose housing systems clashes with the cattle-specific demands of a "pasture-like" subsurface (Benz and Wandel, 2004). It puts too much biomechanical strain on the claw (van der Tol et al., 2003) and is considered one of the risk factors for laminitis and associated claw horn lesions (Cook et al., 2004). Because of this type of inelastic walking surface, various lameness traits increased (Vokey et al., 2001) and the scope of normal behavior was reduced, which indicated inadequate housing and poor welfare (Bammert et al., 1993). This primarily concerns resting, locomotion, and comfort behavior (von Borell and van den Weghe, 2000) as well as estrous behavior (Orihuela, 2000).

The high incidence of lameness (Somers et al., 2003) and the consumers' growing demand for fair-minded livestock husbandry (Bennett et al., 2002; Frewer et al., 2005) provide incentives to look for alternatives, especially regarding floor quality. One possibility is to cover slatted concrete floors with slatted rubber mats. This combines a labor-saving self-cleaning management system with the demands of cattle-friendly flooring. Benz (2002) showed that the self-cleaning function of the slatted floor covered with rubber mats was unimpeded or even improved because of the higher activity of the cows. These rubber mat layers allowed the claws to sink in some millimeters, thus reducing the impact load. In addition, lateral slipping was prevented (Hultgren, 2001), and claw health (Hultgren and Bergsten, 2001) and locomotion in both lame and nonlame cows was improved (Telezhenko and Bergsten, 2005). Similarly, Vanegas et al. (2006) suggested that a soft flooring surface was beneficial for claw health. Furthermore, Platz et al. (2007) showed that when availability of this kind of comfort was restricted, the use of soft flooring correlated with the rank order, which was indicative of the acceptance of soft flooring as an element of comfort in the barn environment.

Species-specific behavior (Haley et al., 1999) and the preference for special locations within the barn (Lowe et al., 2001) were defined as indicators of the ability to cope with the environment. The present study used 
the above-mentioned indicators to assess the effect of a change from concrete slatted flooring to rubberized flooring on floor-associated behavioral elements in a dairy herd.

\section{MATERIALS AND METHODS}

\section{Animals and Housing Environment}

The study was conducted with 50 Brown Swiss dairy cows aged between 3 and $10 \mathrm{yr}$. All cows were lactating (means: $9,006 \mathrm{~kg}$ of milk, 3.54\% true protein, and $4.55 \%$ milk fat). Cows were kept in loose housing and were observed for a change in selected behavioral elements in the course of a step-by-step replacement of the barn floor.

The floor was originally concrete slatted. The rubber mats used for replacement (Type Kura S, Gummiwerke Kraiburg, Tittmoning, Germany) can be produced congruently with the concrete slatted-floor elements in any desired dimensions. According to the specifications of the manufacturer, the mats had a thickness of $3.1 \mathrm{~cm}$, the surface was hammer-blow profiled to enhance grip, the underside profile was rubber studded to allow a maximum deformability of $3.5 \mathrm{~mm}$, and the edges were profiled to permit grooveless lying. Both concrete floor and, after replacement, mats were cleaned daily in the morning by scraping off the manure with a slider.

The barn was characterized by a central feeding alley with feeding mangers, 4 rows of cow stalls ( 2 on either side of the feeding alley arranged in a tail-to-tail configuration), an unforced ventilation system, and a natural day-night cycle. The stalls were deeply littered with straw. Within the stalls, the thickness of the straw bedding varied greatly, from 0 to $20 \mathrm{~cm}$, because of the presence of an old, flat rubber mattress on the base of the stall, which prevented a stable texture of the straw bedding. The measures of the free stalls were as follows: width of $115 \mathrm{~cm}$; bed length of $200 \mathrm{~cm}$; head space of $44 \mathrm{~cm}$; and neck rail height of $108 \mathrm{~cm}$. Both sides of the feeding alley were connected by a walkway leading to the milking parlor. An observation platform was built $4 \mathrm{~m}$ above the feeding alley, where 4 video systems were installed.

Sexual receptivity of all cows was determined based on the progesterone concentration of the milk twice weekly as described by Prakash et al. (1988). Briefly, progesterone values $<0.4 \mathrm{ng} / \mathrm{mL}$ correspond to the early follicular phase, values between 0.4 and $1.0 \mathrm{ng} / \mathrm{mL}$ to the early or late luteal phase, and values $>1.0 \mathrm{ng} / \mathrm{mL}$ indicated full luteal activity. During the experiment, the overall health of the cows was constantly monitored.

\section{Design of the Study}

In conjunction with the stages of floor replacement, the investigation was divided into the following phases:
1. First phase $=$ as-is analysis: concrete slatted floor only, including the measurement of locomotion behavior over 4 wk (see the Behavioral Parameters section) and video observation of comfort, estrus, and resting behavior for 10 consecutive days $(8 \mathrm{~h}$ each, from 0800 to $1600 \mathrm{~h}$ ).

2. Second phase $=$ option to choose between the 2 kinds of floor quality. Floor space entirely rubberized, with the exception of one-half of the walkway to the milking parlor. While one side of the walkway remained concrete, the other was rubberized. After $14 \mathrm{~d}$, the rubber flooring was moved and the sides were switched. In that phase, the cows were observed for which side they used and for how often they changed sides during the walk (observation period for each situation: 6 consecutive days/ $7 \mathrm{~h}$ from 0830 to $1530 \mathrm{~h}$ ).

3. Third phase $=$ entirely rubberized floor space, including the measurement of locomotion behavior over 4 wk (see the Behavioral Parameters section) and video observation of comfort, estrus, and resting behavior for 10 consecutive days ( $8 \mathrm{~h}$ each, from 0800 to $1600 \mathrm{~h}$ ).

\section{Behavioral Parameters}

To evaluate the impact of elastic surfaces on the behavioral elements of movement, comfort, estrus, and resting, behavior was analyzed throughout the step-bystep replacement of the floor surface as follows.

1. Locomotion behavior traits were analyzed by using step-length metrics and the number of steps before and after rubberizing the floor.

a. To ascertain the step length, all cows were observed by video camera during the passage of $4 \mathrm{~m}$ of a cleaned floor area. By means of still photographs and the known measures of slots and slats of the floor element, it was possible to calculate the step length, which was defined as the distance between 2 consecutive floor contacts of the left and the right rear foot. Only cows with at least 2 measurements per phase, and only walks with even courses of motion, were taken into account for the analysis.

b. To obtain the number of steps, 9 cows were equipped for $28 \mathrm{~d}$ with pedometers on their left hind legs, which were changed to the right hind legs after $14 \mathrm{~d}$. The total number of steps was divided by the days of observation to obtain the number of steps per day. The periods of measurement were $28 \mathrm{~d}$ each during phases 1 and 3 of the study to minimize the effect of higher activity during estrus. 
2. Because mounting among females was usually a reliable sign of estrus, occurrences were observed during phases 1 and 3 . In addition, whether any cases of mounting interference or collapse occurred was investigated. Each mounting action that occurred during the period under observation ( $10 \mathrm{~d}, 8 \mathrm{~h}$ each, from 0800 to $1600 \mathrm{~h}$ ) within the herd was recorded (behavior sampling).

3. Comfort behavior traits were defined as elements of individual hygiene, such as licking while standing on 3 legs (licking herself with 1 leg raised from the floor surface) and caudal licking (licking of caudal parts of the body by concave flexion of the lumbar spine), which require firm and secure footing. Each occurrence of these comfort behavior elements during the period under observation was recorded (behavior sampling, phases 1 and 3 of the study, $10 \mathrm{~d}, 8 \mathrm{~h}$ each, from 0800 to $1600 \mathrm{~h}$ ).

4. Analysis of resting behavior was not intended, but was done because of a huge increase in observations of lying in the alley on rubberized floor during the third phase, in contrast to the first phase. Therefore, this type of behavior was analyzed in phases 1 and 3 by a scan sampling method with an interval of $10 \mathrm{~min}$, using the same videotapes as for estrus and comfort behavior $(10 \mathrm{~d}, 8 \mathrm{~h}$ each, from 0800 to $1600 \mathrm{~h}$ ).

\section{Statistical Analyses}

Statistical comparison of groups started with testing for normality (the Kolmogorov-Smirnov test with Lilliefors correction) and equal variance (Levene's median test). If the data fulfilled both criteria, parametric tests were applied (paired $t$-test, $t$-test, one-way ANOVA with the multiple comparisons of Student-Newman-Keuls). If one test failed, nonparametric tests were used (MannWhitney rank sum test). The values are presented as mean \pm standard error of the mean. All these tests were performed by using SigmaStat 3.01 (Systat, Erkrath, Germany). Because of the different numbers of cows in estrus in the respective observational periods, the Ctest according to Przyborowski and Wilenski (1940) was chosen to compare 2 Poisson distributions to facilitate comparison between the numbers of mounting activities. A $P$-value of $<0.05$ was considered statistically significant.

\section{RESULTS}

\section{Walking Behavior (Step Length and Number of Steps)}

Measurement of step length was investigated in the first and third phases. A total of 35 cows fulfilled the criteria, which allowed the measurement to be included. The number of measurements taken for each cow was $3.8 \pm 0.2$ (phase 1) and $5.7 \pm 0.3$ (phase 3 ; mean \pm SEM), respectively. The step length on concrete floor was 58 $\pm 1 \mathrm{~cm}$. On the rubberized floor, step length increased to $70 \pm 1 \mathrm{~cm}(P<0.01)$. There was a low correlation between age and step length on concrete [step length = $66.6-(1.7 \times$ age $) \mathrm{cm} ; \mathrm{R}=0.39 ; P<0.05]$. No correlation was present in the third phase. Consequently, no correlation existed between the age of the cows and the increase in step length.

Nine cows were equipped with step counters (pedometers) for $28 \mathrm{~d}$. The number of daily steps per cow increased from 4,226 \pm 450 on concrete slatted floor (first phase) to $5,611 \pm 495$ on rubberized floor (third phase, $P<0.01)$. By multiplying the daily number of steps by the step length of each cow $(58 \pm 2 \mathrm{~cm}$ and $72 \pm 3 \mathrm{~cm}$, respectively), the daily distance walked by each of these 9 cows was $2.5 \pm 0.3 \mathrm{~km}$ on concrete slatted floor and $4.0 \pm 0.4 \mathrm{~km}$ on rubberized floor.

\section{Herd-Related Estrus Behavior}

Mounting cows were observed in phases 1 and 3 over a period of $10 \mathrm{~d} / 8 \mathrm{~h}$, respectively. During the first period, 28 cows were in a state of sexual receptivity and 23 mounting activities were observed; in the third period, 49 cows were in a state of sexual receptivity and 112 mounting events were observed. Comparing the 2 Poisson means by the C-test, an increase in mounting actions on soft flooring could be observed $(P<0.01)$.

Analysis of the course of mounting revealed that collapsing and slipping occurred in 19 of a total of 23 cases on concrete slatted floor. Although on soft flooring 112 mounting actions were observed without any occurrences of collapsing or slipping, there was no statistical difference.

\section{Comfort Behavior}

Individual elements of hygiene behavior that depend on secure footing, such as licking while standing on 3 legs and caudal licking, increased $(P<0.01)$ on rubberized flooring (Table 1).

\section{Resting Behavior}

Daily observations of the behavior of resting in the alley increased from $6.0 \pm 1.8$ on concrete to $72.2 \pm 4.5$ observations on soft flooring $(P<0.01$; Table 1$)$.

\section{Preferences Regarding Floor Quality}

In the second phase, the cows were offered both kinds of floor quality on the walkway to the milking parlor. 
Table 1. Hygiene and resting behavior observations before and after replacement of concrete slatted floor by slatted soft flooring

\begin{tabular}{lccccc}
\hline & \multicolumn{2}{c}{ Observation per day } & & \\
\cline { 2 - 4 } Recorded behavior $^{1}$ & Concrete floor & Rubber floor & & $\mathrm{n}$ & $P$-value \\
\hline Licking while standing on 3 legs\# & $6.9 \pm 1.3$ & $26.9 \pm 2.4$ & 10 & $<0.01$ \\
Caudal licking\#\# & $3.6 \pm 0.8$ & $24.2 \pm 3.5$ & 10 & $<0.01$ \\
Resting on the alley\# & $6.0 \pm 1.8$ & $72.2 \pm 4.5$ & 10 & $<0.01$ \\
\hline
\end{tabular}

${ }^{1}$ In the first and the third phases, the cows were videotaped for 10 consecutive days $(8 \mathrm{~h}$ each, from 0800 to $1600 \mathrm{~h}$ ). All behaviors counted were summed for each day (mean $\pm \mathrm{SEM}$; \#t-test, \#\#Mann-Whitney rank sum test).

This surface was alternated between the 2 sides of the walkway, with 1 side remaining concrete while the other was rubberized. After $14 \mathrm{~d}$, the rubber flooring was moved and the sides were switched. Whenever the animals had a choice between a concrete or rubber surface, two-thirds of the cows chose the elastic rubber surface $(P<0.01$; Figure 1A) and fewer cows changed sides during the walk $(P<0.01$; Figure 1B). When the surfaces of both sides of the walkway were the same, no preference in use was observed (Figure 1A), and crossing of sides occurred more often $(P<0.01$; Figure 1B).

\section{DISCUSSION}

The present study analyzed behavioral observations as the response of a dairy herd to improvement of flooring. Ethological traits of locomotion, estrous, and hygiene behavior were qualified to obtain information about the needs of cattle with reference to floor quality (Gustafson and Lund-Magnussen, 1995; Cook et al., 2004) and were evaluated on concrete slatted surfaces and on an elastic rubber floor covering. The design of this study was chosen to approximate practical farm realities in the case of floor reconstruction. In doing so, the changes observed in behavior were based, at least in part, on the herd as a whole and not on individual herd members.

Compared with Fregonesi et al. (2004), who observed only marginal behavioral benefits in loose-housed dairy cows with rubber flooring in front of the feed bunk, the present study clearly demonstrated that cows preferred the elasticity of the rubberized floor. This indicator of acceptance of the housing environment (Lowe et al., 2001) was expressed by the significant increase in the number of steps and the step length, supporting the results of Telezhenko and Bergsten (2005). The estimated daily walking distance of $4.0 \mathrm{~km}$ on the rubberized floor approximates distances reported by Funston et al. (1991) for cows on a pasture. Nevertheless, the step lengths of the cows were not really representative of all the steps the cows had taken in the barn because
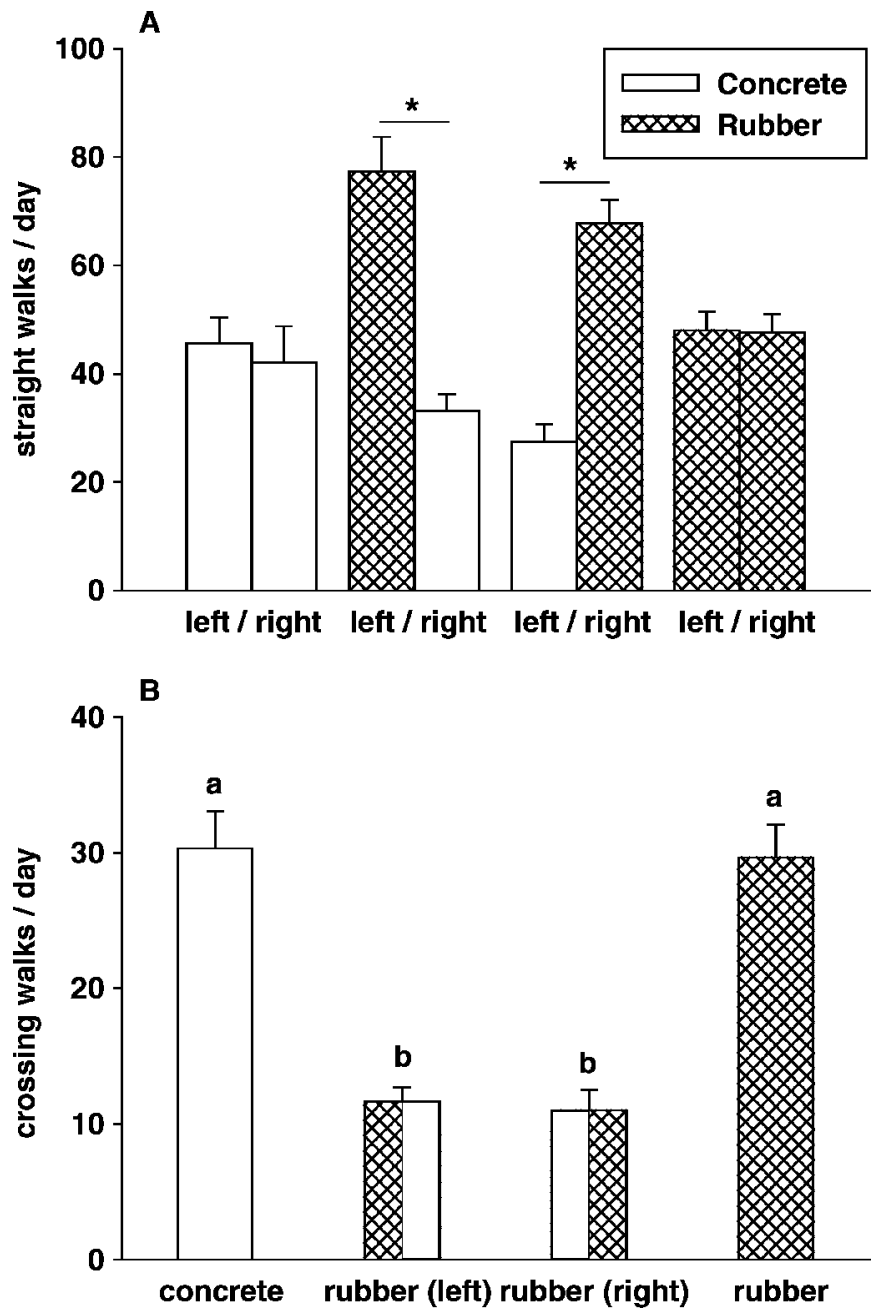

Figure 1. Straight (A) and crossing (B) walks on the way to the milking parlor dependent on alternating change of the floor quality. In different phases, the cows were videotaped for 6 consecutive days ( $7 \mathrm{~h}$ each, from 0830 to $1530 \mathrm{~h}$ ). In the second phase, the cows were alternately offered one side of the walkway to the milking parlor with rubber-coated surface while the other side remained concrete slatted. After $14 \mathrm{~d}$, the 2 floor types were reversed. All straight and crossing walks were summed up for each day (mean \pm SEM). A) $* P<0.01$ ( $t$-test); B) ${ }^{\text {a,b }}$ different letters denote differences at $P<0.01$ (oneway ANOVA). 
they refer to walking in a straight line at a constant speed, which is not the regular pattern. Therefore, the actual distances the cows walked every day were somewhat shorter. The detected increase in step length was not influenced by the age of the cows.

A further sign of the attractiveness of soft flooring was shown by the preference for the rubberized side of the walkway to the milking parlor (Figure 1), which was also expressed by the lower frequency of changes of sides if there was a choice between the 2 floor qualities. The attractiveness of this type of flooring was additionally indicated by an increasing number of observations of cows resting in the alley in the first vs. the third phase. The undesired side effect of resting in the alley may be caused by the described inadequate dimensions and uncomfortable properties of the resting area in the free stalls and points out the necessity of considering the housing environment as a whole. Tucker and Weary (2004) showed that cows spent more time lying down in heavily bedded stalls and hesitated to lie down on inadequately bedded mattresses. Hence, improvements should not be confined to one subarea of the housing environment, but must include associated functional areas as well. Otherwise, the answer to one husbandry problem would lead to a new problem that may be much more severe. One problem that may arise from the additional cows resting in the alley is soiling, especially of the udder, and an increased risk of infections such as mastitis. Nevertheless, the data in the literature are uncommon and contradictory. Schukken et al. (1990) recognized rubber mats used in free stalls as a risk factor for mastitis, whereas Valde et al. (1997) saw a reduced risk of mastitis in barns with rubber mats.

The external conditions for exhibiting estrus were improved considerably by elastic covering of the floor. Regarding complete and uninterrupted mounting actions, the secure footing of the cows resulted in significantly increased frequency of mounting activities. In terms of avoiding injuries, the cows relocated intensive motion sequences into the rubberized floor area (Bammert et al., 1993). According to Dransfield et al. (1998), tolerated and distinctive mounting behavior increased the ratio of pregnancy and exemplified the positive correlation between behavioral benefits and economical aspects.

Elements of comfort behavior that require secure footing increased significantly on rubberized flooring. This can be interpreted as a further indicator for improvement of flooring condition, because cows move with caution on slippery surfaces. Similarly, Hultgren (2001) observed that cows on the rubber-slatted flooring lay down and rose normally and without any increased risk of slipping; they spent $23 \%$ less time preparing to lie down and slipped less frequently during rising.

Further positive proof of the great attractiveness of a rubberized floor was furnished by Platz et al. (2007), who observed that higher ranked animals restricted lower ranked animals in their choice. To avoid rankrelated exclusion among the cows, it seems important to create a barn design that enables all herd members to use comfortable areas within the environment.

In conclusion, covering concrete slatted floor with perforated rubber mats seems a relatively less challenging environment, providing a firm grip and improved ability to express normal behavior. In this context, it is assumed that improved estrus monitoring is of special relevance for management of reproduction. Furthermore, signs of preference and increased comfort behavior seem to be floor-associated indicators that are relatively easy to investigate within the framework of farm welfare assessments.

\section{ACKNOWLEDGMENTS}

The authors wish to thank B. Benz and Gummiwerke Kraiburg, Tittmoning, Germany, for the provision of rubber mats and their technical support, and Monika Thalhammer for the careful linguistic review of the manuscript.

\section{REFERENCES}

Bammert, J., I. Birmelin, B. Graf, K. Löffler, D. Marx, U. Schnitzer, B. Tschanz, and K. Zeeb. 1993. An ethological approach to animal welfare: The supply of needs and avoidance of damage. Tierarztl. Umsch. 48:269-280.

Bennett, R. M., J. Anderson, and R. J. P. Blaney. 2002. Moral intensity and willingness to pay concerning farm animal welfare issues and the implications for agricultural policy. J. Agric. Environ. Ethics 15:187-202.

Benz, B. 2002. Elastische Beläge für Betonspaltenböden in Liegeboxenlaufställen (Elastic coating of concrete slatted floor in loose housing systems). Vol. 394. Max-Eyth-Gesellschaft Agrartechnik, Hohenheim, Germany.

Benz, B., and H. Wandel. 2004. Soft-elastic floorings for paved walking areas in cubicle housing systems for dairy cattle. Pages 212 213 in 13th Int. Symp. and 5th Conf. Lameness in Rumin., Maribor, Slovenia. B. Zemljic, ed. http://ruminantlameness.com/end/ proceedings2004.pdf

Cook, N. B., T. B. Bennett, and K. V. Nordlund. 2004. Effect of free stall surface on daily activity patterns in dairy cows with relevance to lameness prevalence. J. Dairy Sci. 87:2912-2922.

Dransfield, M. B. G., R. L. Nebel, R. E. Pearson, and L. D. Warnick. 1998. Timing of insemination for dairy cows identified in oestrus by a radio telemetric oestrus detection system. J. Dairy Sci. 81:1874-1882.

Fregonesi, J. A., C. B. Tucker, D. M. Weary, F. C. Flower, and T. Vittie. 2004. Effect of rubber flooring in front of the feed bunk on the time budgets of dairy cattle. J. Dairy Sci. 87:1203-1207.

Frewer, L. J., A. Kole, S. van de Kroon, and C. Lawere. 2005. Consumer attitudes towards the development of animal friendly husbandry systems. J. Agric. Environ. Ethics 18:345-367.

Funston, R. N., D. D. Kress, K. M. Havstad, and D. E. Doombos. 1991. Grazing behavior of range and beef cattle differing in biological type. J. Anim. Sci. 69:1435-1442. 
Gustafson, G. M., and E. Lund-Magnussen. 1995. Effect of daily exercise on the getting up and lying down behaviour of tied dairy cows. Prev. Vet. Med. 25:27-36.

Haley, D. B., J. Rushen, and A. M. de Passille. 1999. Behavioural indicators of cow comfort: Activity and resting behaviour of dairy cows in two types of housing. Appl. Anim. Behav. Sci. 71:105-117.

Hultgren, J. 2001. Effects of two stall flooring systems on the behaviour of tied dairy cows. Appl. Anim. Behav. Sci. 73:167-177.

Hultgren, J., and C. Bergsten. 2001. Effect of a rubber-slatted flooring system on cleanliness and foot health in tied dairy cows. Prev. Vet. Med. 52:75-89.

Lowe, D. E., R. W. J. Steen, and V. Beattie. 2001. Preference of housed finishing beef cattle for different floor types. Anim. Welf. 10:395-404.

Orihuela, A. 2000. Some factors affecting the behavioural manifestation of oestrus in cattle: A review. Appl. Anim. Behav. Sci. 70:1-16.

Platz, S., F. Ahrens, J. Bendel, H. Meyer, and M. H. Erhard. 2007. Rank correlated use of soft flooring by dairy cattle. Anim. Welf. 6:255-257.

Prakash, B. S., H. H. D. Meyer, and D. F. M. van de Wiel. 1988. Sensitive enzyme immunoassay of progesterone in skim milk using second-antibody technique. Anim. Reprod. Sci. 16:225-235.

Przyborowski, J., and H. Wilenski. 1940. Homogeneity of results in testing samples from Poisson series. Biometrika 31:313-323.

Schukken, Y. H., F. J. Grommers, D. Vandegeer, H. N. Erb, and A. Brand. 1990. Risk-factors for clinical mastitis in herds with a low bulk milk somatic-cell count. 1. Data and risk-factors for all cases. J. Dairy Sci. 73:3463-3471.
Somers, J. G. C. J., K. Frankena, E. N. Noordhuizen-Stassen, and J. H. M. Metz. 2003. Prevalence of claw disorders in Dutch dairy cows exposed to several floor systems. J. Dairy Sci. 86:2082-2093.

Telezhenko, E., and C. Bergsten. 2005. Influence of floor type on the locomotion of dairy cows. Appl. Anim. Behav. Sci. 93:183-197.

Tucker, C. B., and D. M. Weary. 2004. Bedding on geotextile mattresses: How much is needed to improve cow comfort. J. Dairy Sci. 87:2889-2895.

Valde, J. P., D. W. Hird, M. C. Thurmond, and O. Osteras. 1997. Comparison of ketosis, clinical mastitis, somatic cell count, and reproductive performance between free stall and tie stall barns in Norwegian dairy herds with automatic feeding. Acta Vet. Scand. 38:181-192.

van der Tol, P. P. J., J. H. M. Metz, E. N. Noordhuizen-Stassen, W. Back, C. R. Braam, and W. A. Weijs. 2003. The vertical ground reaction force and the pressure distribution on the claws of dairy cows while walking on a flat substrate. J. Dairy Sci. 86:2875-2883.

Vanegas, J., M. Overton, S. L. Berry, and W. M. Sischo. 2006. Effect of rubber flooring on claw health in lactating dairy cows housed in free-stall barns. J. Dairy Sci. 89:4251-4258.

Vokey, F. J., C. L. Guard, H. N. Erb, and D. M. Galton. 2001. Effects of alley and stall surfaces on indices of claw and leg health in dairy cattle housed in a free stall barn. J. Dairy Sci. 84:2686-2699.

von Borell, E., and S. van den Weghe. 2000. Development of criteria for the assessment of housing systems for cattle, pigs and laying hens relating to animal welfare and environmental impact. Züchtungskunde 72:8-16.

Wagner-Storch, A. M., R. W. Palmer, and D. W. Kammel. 2003. Factors affecting stall use for different free stall bases. J. Dairy Sci. 86:2253-2266. 